ARTICLE

\title{
Widespread increase in dynamic imbalance in the Getz region of Antarctica from 1994 to 2018
}

\author{
Heather L. Selley (1) ${ }^{1 凶}$, Anna E. Hogg 2 , Stephen Cornford ${ }^{3}$, Pierre Dutrieux (1) 4,10, Andrew Shepherd ${ }^{1}$,

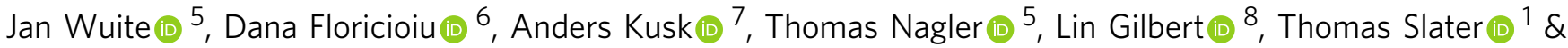 \\ Tae-Wan Kim (iD) 9
}

The Getz region of West Antarctica is losing ice at an increasing rate; however, the forcing mechanisms remain unclear. Here we use satellite observations and an ice sheet model to measure the change in ice speed and mass balance of the drainage basin over the last 25-years. Our results show a mean increase in speed of $23.8 \%$ between 1994 and 2018, with three glaciers accelerating by over $44 \%$. Speedup across the Getz basin is linear, with speedup and thinning directly correlated confirming the presence of dynamic imbalance. Since 1994, $315 \mathrm{Gt}$ of ice has been lost contributing $0.9 \pm 0.6 \mathrm{~mm}$ global mean sea level, with increased loss since 2010 caused by a snowfall reduction. Overall, dynamic imbalance accounts for two thirds of the mass loss from this region of West Antarctica over the past 25-years, with a longer-term response to ocean forcing the likely driving mechanism.

\footnotetext{
${ }^{1}$ Centre for Polar Observation and Modelling, School of Earth and Environment, University of Leeds, Leeds, UK. ${ }^{2}$ School of Earth and Environment, University of Leeds, Leeds, UK. ${ }^{3}$ Department of Geography, Swansea University, Swansea, UK. ${ }^{4}$ Lamont-Doherty Earth Observatory, Colombia University, New York, USA. ${ }^{5}$ ENVEO IT GmbH, Innsbruck, Austria. ${ }^{6}$ German Aerospace Centre (DLR), Remote Sensing Technology Institute, Wessling, Germany. ${ }^{7}$ DTU Space, National Space Institute, Technical University of Denmark, Lyngby, Denmark. ${ }^{8}$ Mullard Space Science Laboratory, Department of Space \& Climate Physics, University College London, London, UK. ${ }^{9}$ Korea Polar Research Institute, Incheon, South Korea. ${ }^{10}$ Present address: British Antarctic Survey, Natural Environment Research Council (NERC), Cambridge, UK.凶email: eehls@leeds.ac.uk
} 


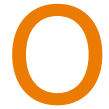
ver the last 25 years, the Antarctic Ice Sheet has contributed $7.6 \pm 3.9 \mathrm{~mm}$ to global sea level ${ }^{1}$. Observations have shown that ice loss from Antarctica is dominated by the low-lying, marine-based sectors of West Antarctica ${ }^{1-4}$, where glaciers in the Amundsen Sea Sector have thinned, accelerated, and grounding-lines have retreated since the $1940 \mathrm{~s}^{5-8}$. Elsewhere, ice shelves on the Antarctic Peninsula have retreated $^{9}$ and collapsed ${ }^{10,11}$, triggering a dynamic response as the flow of grounded ice is unbuttressed ${ }^{12}$. Dynamic imbalance in West Antarctica is driven by incursions of warm modified Circum-polar Deep Water (mCDW) melting the floating ice ${ }^{3,13}$, with the interannual and long-term variability of ocean temperatures linked to atmospheric forcing associated with the El Nino-Southern Oscillation (ENSO) $)^{14,15}$ and anthropogenic forcing ${ }^{16}$, respectively. The ice sheet contribution to the global sea level budget remains the greatest uncertainty in future projections of sea level rise ${ }^{17}$, driven in part by positive feedbacks such as the Marine Ice Sheet Instability (MISI) ${ }^{18,19}$, and with the most extreme scenarios ( $>1 \mathrm{~m}$ by 2100 ) only possible through the onset of Marine Ice Cliff Instability (MICI $^{20,21}$. Satellite data have shown that in Antarctica the dynamic ice loss $(6.3 \pm 1.9 \mathrm{~mm}$ sea level equivalent (sle) $)$ is $86 \%$ greater than the modest reduction in surface mass $(0.9 \pm 1.1 \mathrm{~mm}$ sle) since the $1990 \mathrm{~s}^{22}$. However, both long-term and emerging new dynamic signals must be accurately measured in order to better understand how ice sheets will change in the future. Since $2008,88 \%$ of the observed ice speedup has occurred on glaciers located in the Amundsen Sea, Getz and Marguerite Bay sectors ${ }^{23}$. However, the timing and pace of dynamic imbalance is poorly characterised in regions that are observed less frequently, and uncertainty remains about the physical mechanisms driving this change.

The Getz drainage basin lies at the coastal margin of Marie Byrd Land, and covers $10.2 \%\left(177,625 \mathrm{~km}^{2}\right)$ of the West Antarctic Ice Sheet ${ }^{8}$. Ice flows from the ice sheet into the Getz Ice Shelf through 14 distinct glaciers that extend $\sim 145 \mathrm{~km}$ inland, and flow at average speeds of over $500 \mathrm{~m} /$ year at the grounding line (Fig. 1a). The region is characterised by a $650-\mathrm{km}$-long 25 - to $110-\mathrm{km}$-wide ice shelf, the eighth largest in Antarctica, which provides buttressing support to the grounded ice. While grounding line retreat has been observed since 2003 (ref. ${ }^{24}$ ), the ice shelf is anchored at its seaward margin by eight large islands and over 23 pinning points which stabilise the ice shelf calving front, resulting in a relatively small area change over the past three decades ${ }^{25,26}$. Despite the absence of significant area change, strong ice shelf thinning $\left(-16.1 \mathrm{~m} /\right.$ decade) has been observed since the $1990 \mathrm{~s}^{27}$, producing one of the largest sources of fresh water input to the Southern Ocean ${ }^{28}$, more than double that of the neighbouring Amundsen Sea ice shelves ${ }^{29}$. The complex network of topographic rises at the ice front channel ocean currents under the sub-ice shelf cavity, driving a highly localised spatial pattern of ice thinning, with the strongest rates observed at the grounding line ${ }^{30}$. Spatially variable ocean forcing is expected along the Getz coastline due to its zonal extent, about half the length of the West Antarctic Ice Sheet margin, and its location between the colder Ross and warmer Amundsen Seas ${ }^{25}$.

Over the past 30 years, the Getz drainage basin has lost $\sim 410$ Gt of ice mass ${ }^{8}$, at a rate that has increased by over $40 \%$ since 2010 (ref. ${ }^{31}$ ). The Flood, McCuddin and Executive Committee mountain ranges provide regions of high elevation bed topography at the ice divide, producing a broadly prograde bed slope across the basin ${ }^{32}$. This geometry prevents inland propagation of strong ice sheet thinning 8 (Fig. 1c) and makes the region less susceptible to onset of MISI in comparison to the retrograde sloping marine-based glaciers in the neighbouring Amundsen Sea Embayment ${ }^{18,19}$. The pattern of snowfall is heterogeneous across the basin, with the highest rates deposited on steeply sloping topography aligned orthogonal (i.e. West to East) to the prevalent direction of atmospheric moisture flux ${ }^{33}$. While summer surface melt is limited to the lower elevation ice shelf ${ }^{33}$, interannual variability in Surface Mass Balance (SMB) is driven by the Amundsen Sea Low, which accounts $40 \%$ of the surface mass and $21 \%$ of the surface melt variability ${ }^{34}$. Partitioning the influence of both surface mass and ice dynamic signals in Antarctica is key to understanding the atmospheric and oceanic forcing mechanisms driving recent change ${ }^{35}$. Studies suggest that thinning of glaciers flowing into the Getz Ice Shelf are greater than the estimated increase in ice discharge alone, indicating that surface processes are at least in part responsible for the observed thinning 8,36 . However, a multi-decadal, continuous ice velocity record is required to perform a detailed assessment of the change in ice flux. In this study, we use satellite data to measure the change in ice speed of glaciers in the Getz drainage basin from 1994 to 2018, to assess the localised pattern of dynamic imbalance in this large and complex sector of West Antarctica. Our results show that between 1994 and 2018, widespread speedup has occurred on the majority of glaciers in the Getz drainage basin of West Antarctica. A mean speed increase of $23.8 \%$ was observed, with three glaciers accelerating by over $44 \%$. Since $1994,315 \mathrm{Gt}$ of ice has been lost, contributing $0.9 \pm 0.6 \mathrm{~mm}$ to global sea levels. Increased ice loss since 2010 was driven by a snowfall reduction, with dynamic imbalance likely driven by a longer-term response to ocean forcing.

\section{Results}

Ice velocity. Our velocity measurements show that the Getz coastline is characterised by 14 major flow units, with two glaciers reaching mean speeds of over $1 \mathrm{~km}$ /year in 2018, and regions of fast flow generally limited to within $\sim 40 \mathrm{~km}$ of the grounding line (Fig. 1a). Nine of the 14 major glaciers are unnamed, with flow units 10 to 14 at the far West of the sector (Fig. 1a) corresponding to DeVicq, Berry, Venzke, Hull and Land Glaciers, respectively. We extracted velocity measurements along 14 flow-line transects located on the fast-flowing trunk of glaciers in the Getz study region (Figs. 1a and 2). Measurements were extracted from a $5-\mathrm{km}$ diameter region located at the grounding line of each flow unit. The fastest flowing ice streams in the Getz drainage basin are located in the West of the sector, where Hull Glacier (flow unit 13) and Land Glacier (flow unit 14) flow at speeds of up to $1.4 \pm 0.2 \mathrm{~km} /$ year (Table 1 and Supplementary Fig. 1). Slower moving ice is transported over the Executive Committee, McCuddin and Flood mountain ranges inland of Marie Byrd Land, into the Amundsen Sea via the Getz Ice Shelf through which the majority of glaciers flow. The slowest moving glaciers are found in the far East of the Getz drainage basin, where flow unit 1 located to the West of Martin Island, and flow unit 3 located to the West of Wright Island, flow at a speeds of $174 \pm 12 \mathrm{~m} /$ year and $183 \pm 14 \mathrm{~m} /$ year, respectively (Table 1 and Supplementary Fig. 1).

The spatial coverage of the ice velocity observations is influenced by both the density of satellite data acquisitions and the performance of the image processing techniques used to measure ice speed. In the Getz drainage basin, the absence of visible features on the ice sheet surface and the susceptibility of the snow surface to change in response to local weather events makes the ice sheet interior a particularly challenging region to measure. Our results show that in general, ice speed measurements are limited to within $\sim 200 \mathrm{~km}$ of the calving front due to the combined effect of weather and the geographical coverage of the satellite images acquired across the Getz study region, with consistently poorer coverage inland (Supplementary Fig. 2). We observe the lowest spatial coverage in 1998, where velocity measurements are retrieved over $2 \%\left(3432 \mathrm{~km}^{2}\right)$ of the Getz 

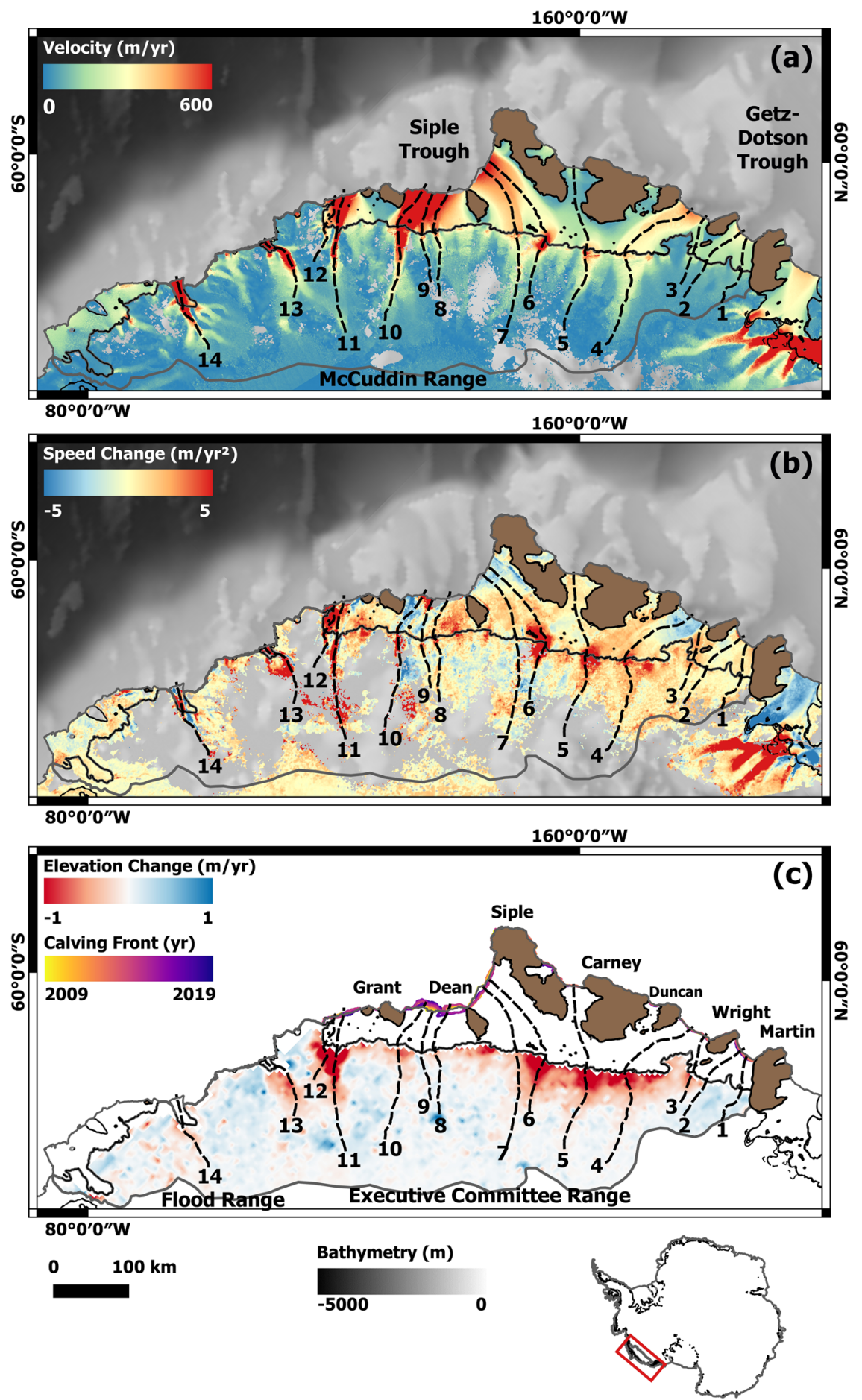

Fig. 1 Ice speed, speed change and thinning over the Getz basin. a Ice speed in the Getz drainage basin of Marie Byrd Land, measured in 2018 using Interferometric Wide (IW) mode synthetic aperture radar (SAR) data acquired by the Sentinel-1a/b satellites. The grounding line location (solid black line ${ }^{67}$ ), inland limit of the drainage basin (solid grey line) and the location of 14 flow line profiles (dashed black lines) are also shown. Profiles 1 to 9 are located on unnamed glaciers; however, 10 to 14 correspond to DeVicq, Berry, Venzke, Hull and Land Glaciers, respectively. Measurements are superimposed on BEDMAP2 bedrock topography ${ }^{32}$. b A map of the observed rate of change in ice speed between 1994 and 2018 . c Ice sheet elevation change with Firn Densification Model (FDM) correction applied from 1992 to 2017 , measured using satellite radar altimetry data ${ }^{8}$. The names of islands and ice rises (brown area) bordering the Getz Ice Shelf are also indicated. The calving front location is shown from 2009 in yellow to 2019 in purple, see Supplementary Fig. 7 for a zoom of the calving front change.

drainage basin (Supplementary Table 1). The highest spatial coverage was observed during the 2014 and 2016 epochs, where ice speed is measured over $154,209 \mathrm{~km}^{2}(90 \%)$ and $155,518 \mathrm{~km}^{2}$ (90\%) of the Getz basin, respectively (Supplementary Table 1).
On average, all glaciers in the Getz drainage basin were surveyed on at least ten occasions since 1994. Though the historical observations from the 1990s have poor spatial coverage, they provide an invaluable reference measurement for glaciers in the 

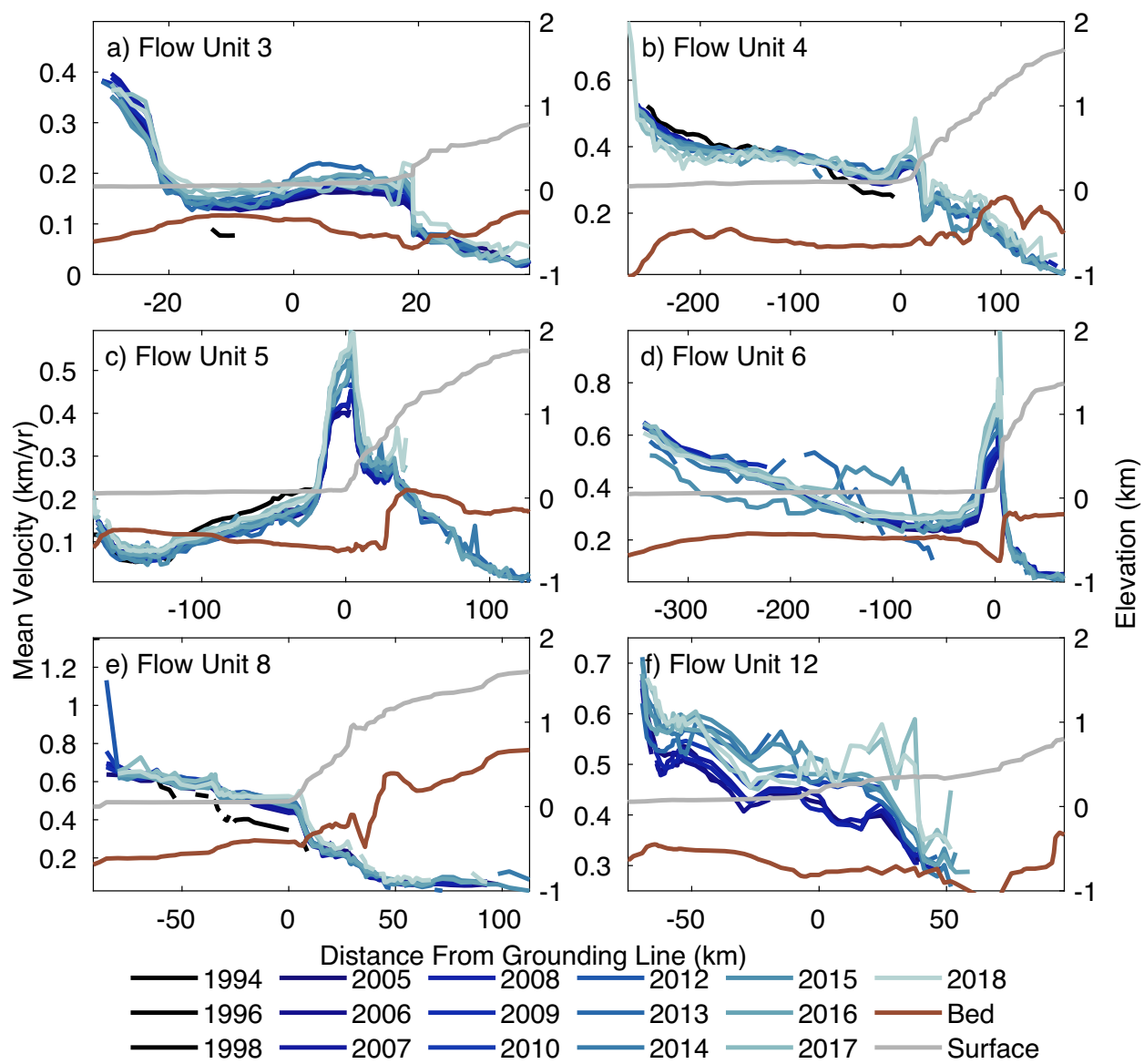

Fig. 2 Ice speed profiles. Profiles of ice speed observed between 1994 (dark blue) and 2018 (light blue) extracted along flow-line transects located on the central trunk of outlet glaciers in the Getz study region. The ice surface elevation (grey line) and bed elevation (brown line) from BEDMAP2 (ref. 32 ) extracted along the same profile is also shown. The $x$-axis is shown as distance from the grounding line 67 , with positive values indicating the inland section of the profile on the ice sheet, and negative values indicating seaward locations. Flow units 3 (a), 4 (b), 5 (c), 6 (d), 8 (e) and 12 (f) are presented here, with all 14 flow line profiles shown in Supplementary Fig. 8.

Table 1 The observed mean ice speed from 2018, the observed and modelled rate of change in ice speed, the observed total and percentage change in ice speed from 1994 to 2018.

\begin{tabular}{|c|c|c|c|c|c|c|c|c|c|}
\hline $\begin{array}{l}\text { Flow } \\
\text { unit }\end{array}$ & $\begin{array}{l}2018 \text { Mean } \\
\text { speed (m/yr) }\end{array}$ & $\begin{array}{l}\text { Observed } \\
\text { rate of } \\
\text { speed } \\
\text { change } \\
\left(\mathrm{m} / \mathbf{y r}^{2}\right) \\
\end{array}$ & $\begin{array}{l}\text { Modelled } \\
\text { rate of } \\
\text { speed } \\
\text { change } \\
\left(\mathrm{m} / \mathrm{yr}^{2}\right)\end{array}$ & $\begin{array}{l}\text { Observed total } \\
\text { speed up } \\
\text { over } 25 \text { years } \\
(\mathrm{m} / \mathrm{yr})\end{array}$ & $\begin{array}{l}\text { Observed } \\
\text { percentage } \\
\text { speed change } \\
\text { over } \\
25 \text { years (\%) }\end{array}$ & $\begin{array}{l}\text { Rate of elevation } \\
\text { change } \\
\text { 1992-2017 } \\
(\mathrm{m} / \mathrm{yr})\end{array}$ & $\begin{array}{l}\text { Grounding line } \\
\text { migration } \\
\text { 1996-2017 (km) }\end{array}$ & $\begin{array}{l}\text { Ice thickness } \\
\text { (m) }\end{array}$ & $\begin{array}{l}\text { Bed elevation } \\
\text { (m) }\end{array}$ \\
\hline 1 & $173.7 \pm 11.5$ & 0.7 & 0.8 & 18.6 & 10.7 & 0.0 & -1.3 & 649 & -540 \\
\hline 2 & $192.2 \pm 17.2$ & 0.2 & 0.1 & 5.5 & 2.9 & -0.2 & -1.1 & 674 & -594 \\
\hline 3 & $182.6 \pm 14.4$ & 1.9 & 1.9 & 46.5 & 25.5 & -0.7 & -2.7 & 639 & -541 \\
\hline 4 & $390.7 \pm 33.3$ & 3.7 & 3.4 & 92.4 & 23.6 & -1.0 & - & 775 & -651 \\
\hline 5 & $532.4 \pm 36.1$ & 10.5 & 9.1 & 263.4 & 49.5 & -1.6 & - & 728 & -613 \\
\hline 6 & $668.8 \pm 90.8$ & 15.6 & 15.2 & 391.2 & 58.5 & -1.8 & - & 851 & -727 \\
\hline 7 & $424.8 \pm 42.2$ & 1.0 & 2.1 & 24.5 & 5.8 & -0.5 & -2.5 & 638 & -552 \\
\hline 8 & $518.8 \pm 59.1$ & 2.0 & 5.4 & 50.4 & 9.7 & -0.5 & - & 501 & -418 \\
\hline 9 & $511.2 \pm 64.6$ & 2.8 & 3.8 & 69.4 & 13.6 & -0.1 & - & 552 & -473 \\
\hline 10 & $879.2 \pm 149.1$ & 9.1 & 11.4 & 228.2 & 26.0 & -0.6 & - & 659 & -535 \\
\hline 11 & $744.3 \pm 125.0$ & 5.7 & 5.1 & 141.5 & 19.0 & -2.2 & - & 913 & -659 \\
\hline 12 & $467.8 \pm 65.5$ & 8.2 & 6.2 & 205.5 & 43.9 & -1.3 & - & 995 & -806 \\
\hline 13 & $1397.6 \pm 163.7$ & 11.4 & 6.0 & 285.8 & 20.4 & -0.4 & - & 674 & -524 \\
\hline 14 & $1281.1 \pm 122.6$ & 8.0 & 7.3 & 198.9 & 15.5 & -0.6 & - & 701 & -560 \\
\hline
\end{tabular}

All measurements were extracted from a 5-km-diameter region at the grounding line, on all 14 flow lines (Fig. 1a) in the Getz study region. Measurements of grounding line migration are provided where observations exist, along with the mean FDM corrected ice thickness and bed elevation ${ }^{32}$ also extracted from the $5 \mathrm{~km}$ region at the grounding line. Ice sheet elevation change 8 was extracted from a 20 $\mathrm{km}$-diameter region due to the coarser spatial resolution of this dataset. Italics denote flow units (11 and 13 ) with less than $70 \%$ coverage in the $5 \mathrm{~km}$ region on the observed speed change map. Grounding line migration is calculated as the distance along the central flow line the grounding line has moved, negative indicating a movement inland.

central to Northern part of the Getz sector, where no other ice speed estimate is available. In all other years except for 2009 and 2012 , the majority $(>55 \%)$ of the ice sheet margin is observed (Supplementary Table 1).
Change in ice speed. Our results show that the majority of glaciers in the study area have accelerated since the 1990s, with seven glaciers speeding up by over $20 \%$ (flow units 3 to $6,10,12$ and 13 ) (Table 1) based on a linear rate (Supplementary Figs. 1d, 3 and 4). 
In regions without observational data from the 1990s, this trend may not be tightly constrained by the data; however, we find good agreement between the modelled and observed rates (Supplementary Fig. 1). In order to asses dynamic imbalance across the Getz drainage basin over the 25-year study period, we generated a map of change in ice speed by fitting a linear trend to every pixel in the study region, for all 16 observed ice speed maps from 1994 to 2018 (Fig. 1b). We required all trends to include a minimum of 5 -years of velocity observations, not necessarily consecutively, and we filtered the output using a 95\% confidence interval on the fit. The largest percentage increase in ice speed was observed on flow units 5 and 6 in the centre of the Getz basin behind Siple and Carney Islands, where ice flow has increased by $50 \%$ and $59 \%$, respectively, since 1994 (Fig. $1 \mathrm{~b}$ and Table 1). This corresponds to two of the fastest speed change rates which are also observed on flow units 5 and 6, with speeds increasing by $10.5 \mathrm{~m} / \mathrm{year}^{2}$ and $15.6 \mathrm{~m} /$ year $^{2}$, respectively, and DeVicq Glacier (flow unit 10) in the far West, where speeds have increased by $9.1 \mathrm{~m} /$ year $^{2}$ (Table 1 and Supplementary Fig. 1d). The smallest change in speed was observed on flow units 1 and 2 in the far East of the Getz basin (Fig. 1b) where ice speeds have increased at rates of under $0.7 \mathrm{~m} / \mathrm{year}^{2}$ since 1994 (Table 1 and Supplementary Fig. 1d). While we observed the second largest speed up on flow unit 13, the spatial coverage of the speed change observations within the $5 \mathrm{~km}$ region at the grounding line is $40 \%$, substantially lower than the $>85 \%$ coverage on all 12 other ice streams. Consequently, we excluded this glacier, and Berry Glacier (flow unit 11) (70\%), from further detailed analysis to avoid overinterpreting results in regions of poorer coverage.

We find that the glaciers that have sped up the most correspond to the regions of strongest ice sheet thinning, greater than $-1.0 \mathrm{~m} /$ year (Fig. $1 \mathrm{c}$ and Table 1), which in some cases extends up to $75 \mathrm{~km}$ inland (flow units 5, 6, 11 and 12). We directly compared the rate of relative ice speedup (\%) with the amount of ice sheet thickness change as a proportion of the total ice thickness, and found a linear relationship between the two parameters $\left(R^{2}=0.74\right)$ as required by the theory of mass conservation $^{37}$ (Fig. 3a). This result indicates that an $\sim 50 \%$ increase in ice speed will cause an $\sim 5 \%$ decrease in glacier thickness due to ice dynamic processes, and suggests that there is no significant bias in the velocity or surface elevation change observations.

Optimised ice flow model. We employed an optimised ice flow model to complement the satellite measurements by filling in gaps in the 16 annual velocity maps, and to investigate the processes driving change in ice speed. We find that the observed and modelled pattern of speed change agrees well (Supplementary Fig. 5a), with a mean difference of $0.18 \mathrm{~m} / \mathrm{year}^{2}$. The results show the number and distribution of flow units has remained uniform over the 25-year study period, the largest area of speedup is observed in the central section of the Getz drainage basin (Fig. 1b). The two spatially extensive but distinct regions of speedup, $\sim 300 \mathrm{~m} /$ year since 1994, are observed at the grounding lines of flow units 5 and 6 . However, in both cases, this increase is concentrated around the fastest flowing grounded ice, and does not extend to the ice shelf calving front. Strong localised speedup, of over $90 \mathrm{~m} /$ year since 1994, is observed on six other glaciers in the Getz basin, including flow unit 4, along with DeVicq, Berry, Venzke, Hull and Land Glaciers (flow units 10, 11, 12, 13 and 14, respectively) (Table 1). The observed speedup is again strongest at the grounding line, and in all cases apart from Venzke Glacier (flow unit 12), does not extend to the ice shelf calving front.

Mass balance. Our results show that, on average, ice discharge from the Getz drainage basin is $116.4 \mathrm{Gt} /$ year, with $23 \mathrm{Gt} /$ year more ice flux in 2018 compared with 1994. The central region contributes the highest mass loss from the drainage basin partially due to it containing the fastest flowing and thickest ice. Cumulatively, the Getz study region has lost $315 \mathrm{Gt}$ of ice mass since
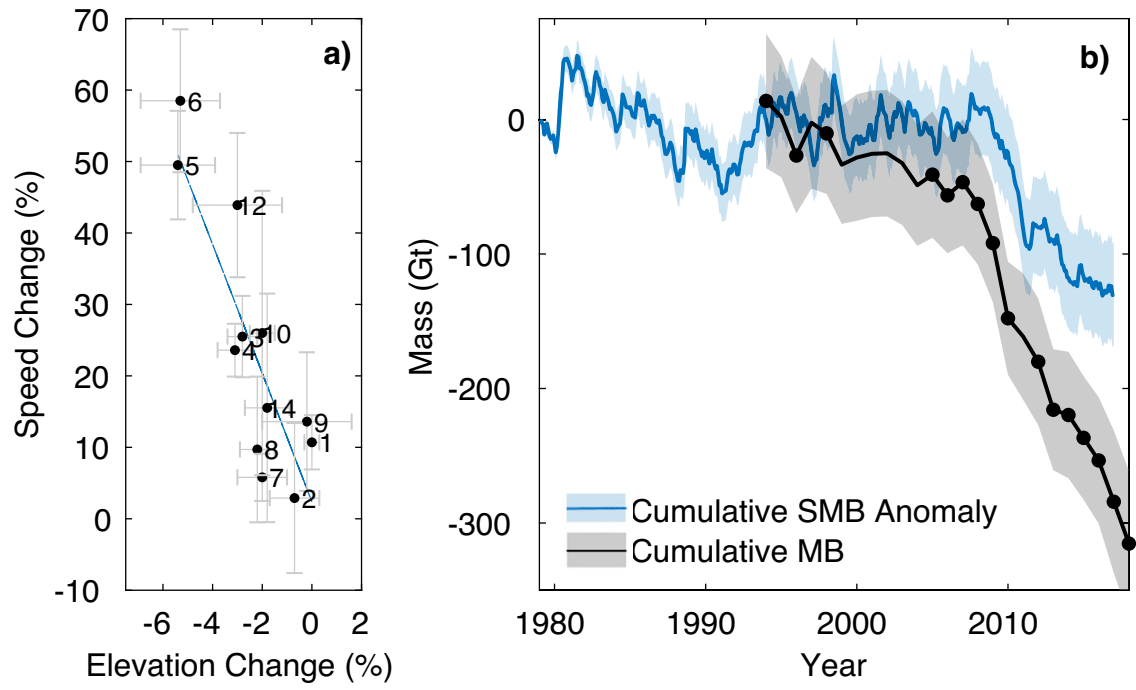

Fig. 3 Ice dynamic relationship and mass balance. a Total change in speed since 1994 as a percentage of 2018 velocity, scattered against change in ice thickness as a proportion of the total ice thickness. The number of each flow unit is annotated on each point, and the linear relationship (blue dashed line) between the two variables has an $R^{2}$ value of 0.74 . Flow units 11 and 13 excluded due to low coverage of the velocity observations (<70\%) in the $5 \mathrm{~km}$ region at the grounding line. The uncertainty bars (grey) are the standard deviation of the values extracted within the $5 \mathrm{~km}$ buffer region for each glacier. b The Cumulative Mass Balance from the Getz drainage basin between 1994 and 2018 (black line), filled black circles represent years with velocity observations, along with the cumulative Surface Mass Balance (SMB) anomaly from 1979 to 2016 (blue line) 68 . The mass balance uncertainty is calculated as the discharge error combined with the error in SMB. Discharge error is the combination of the percentage errors in ice thickness and velocity along the flux gate. For years of model discharge without a corresponding observation map, we assume the percentage error of the nearest observation year and add an additional standard deviation to the velocity error. We assume the uncertainty in the annual SMB trend to be $20 \%$ in line with previous studies 23,69 and the cumulative uncertainty is the root sum square of the annual errors, assuming that they are not correlated over time. 
1994 with an uncertainty estimate of $\pm 46 \mathrm{Gt} /$ year, contributing $0.9 \pm 0.6 \mathrm{~mm}$ global mean sea level equivalent over the last 25 years, with mass loss 4.4 times higher in the 2010s than it was in the 1990s (Fig. 3b). The SMB anomaly shows that following a short increase in surface mass in the early 1990s, the cumulative anomaly remained relatively constant from 1995 to 2008. From $\sim 2008$ to 2017 , there was a substantial $(\sim 150 \mathrm{Gt})$ decrease in the cumulative SMB anomaly in the Getz basin, which is dominated by an anomalously low snowfall year in 2010 when snowfall was $57.3 \%$ lower than the annual mean over the 25 -year period (103.8 $\mathrm{Gt} /$ year). Mass loss from the Getz drainage basin has therefore been caused by a linear increase in ice speed since the 1990s of $23.8 \%$, exacerbated by a surface mass deficit in 2010 . This shows the influence of both ice dynamic and surface mass processes in this region of Antarctica, with dynamic processes responsible for approximately two-thirds (57.4\%) of the total mass loss. Our estimate of mass balance from the Getz sector using the input-output method compares well to other independent estimates of ice loss from the region ${ }^{8,38,39}$, with differences attributed to mismatch between the precise study periods, spatial domain and ice thickness definitions.

\section{Discussion}

Two previous studies have measured the change in speed of glaciers in the Getz drainage basin, with the largest increase in ice flow observed behind Siple Island and at the far West of the sector between $2007 / 8$ to $2014 / 15$ (refs. ${ }^{23,36}$ ). Our results extend and fill gaps in the spatial coverage, and show that the largest and most extensive ice speedup is concentrated on flow units 5 and 6 in the centre of the Getz drainage basin (Fig. 1b). Combined, these two glaciers account for $41.1 \%$ of the total increase in ice speed across the Getz sector since 1994 (Table 1). The zone of high percentage speedup coincides with the thickest and most rapidly thinning part of the Getz Ice Shelf behind Siple and Carney Islands 27,30 . This study confirms that the five fastest flowing glaciers in the far West of the Getz drainage basin (flow units 10 to 14) have also undergone a significant increase in ice speed since 1994 ( $25 \%$ on average), accounting for $39.7 \%$ of the total speedup in the region (Table 1). DeVicq Glacier (flow unit 10) has been posed as a possible route through which future instability might propagate in Marie Byrd Land, due to a deep bedrock trough that lies over $300 \mathrm{~m}$ below sea level at the grounding line and extends over $200 \mathrm{~km}$ inland. Model studies have indicated that despite the glacier's geometry it is not susceptible to imbalance even with the presence of warmer ocean water in the Amundsen $\mathrm{Sea}^{40}$. In contrast, our results show that although limited to $\sim 40 \mathrm{~km}$ inland of the grounding line, this glacier has undergone the fourth largest speed up in the Getz region over the last 25 years, with ice speeds increasing at a rate of $9.1 \mathrm{~m} /$ year $^{2}$ (Table 1$)$.

Berry, Venzke and Land Glaciers (flow units 11, 12 and 14) correspond to a region of orographically driven high snowfall in excess of $3000 \mathrm{~mm}$ w.e./year, that is resolved by high spatial resolution $(5.5 \mathrm{~km})$ regional climate models ${ }^{41}$. The Getz drainage basin has the highest surface mass variability in Antarctica outside of the peninsula ${ }^{8}$, and the cumulative surface mass anomaly shows that since $\sim 2008$ snowfall into the basin has been significantly lower than the long-term mean (Fig. 3b). Our multidecadal time-series of speed change shows that on all glaciers in the Getz study region, the observed increase in ice flow has been relatively linear over the past 25 years (Supplementary Fig. 1d). The accelerated mass loss from the Getz sector since 2010 observed by this study (Fig. 3b) and others ${ }^{8,39}$, has therefore likely been driven by both the long-term gradual increase in dynamic imbalance combined with the effect of a short-term surface mass deficit. This shows that extreme snowfall years have a significant influence on the mass balance of the whole drainage basin, and suggests that localised regions of high snowfall only resolved by high-resolution models may impact the balance of individual glaciers.

The Getz drainage basin is located in the transition zone between the cooler Ross Sea and the warmer Amundsen Sea, with warmer ocean potential temperatures found in the West of the Getz study region (Fig. 4c). Observations suggest that over the last three decades ocean temperatures in West Antarctica have warmed offshore ${ }^{42}$, with periodic incursions of warm $\mathrm{mCDW}$ onto the continental shelf driving shorter term sub-decadal to decadal variability $14,15,25$. In the Getz region, annual mean temperature depth profiles collected from ship-based CTD sampling between 1994 and 2018, show annual variation in the depth of the thermocline dividing a cold and fresh upper layer from mCDW (Fig. 4b). In 1994, 2000, 2012 and 2014, the thermocline was $\sim 200 \mathrm{~m}$ deeper, leading to cooler integrated ocean heat content, in contrast to warmer years in 2007, 2009, 2016 and 2018 when the thermocline was shallower. These observations are in line with previous studies of ocean temperature, and have been linked to the ocean response to interannual atmospheric variability ${ }^{25,28}$. Change in thermocline depth is observed as a band of temperature variability between $\sim 500$ and $800 \mathrm{~m}$ below sea level, and is particularly strong in the West of the Getz sector (Fig. 4d). The relatively short distance between the continental shelf break and the Getz calving front makes ocean heat content particularly sensitive to atmospheric forcing at the continental shelf break, even more so than in the Eastern Amundsen Sea ${ }^{43,44}$, consistent with the large ocean heat content variability (Fig. $4 \mathrm{~b}$ ).

In order for spatial and temporal variability in ocean temperatures to affect the rate of ice melt and dynamic imbalance of the Getz drainage basin, warmer ocean water must be transported from the open ocean under the ice shelf at depth (below $\sim 400 \mathrm{~m}$ ), where it can come into contact with and melt deeply grounded ice. Ocean circulation under Antarctic ice shelves is directed by the Coriolis force, which causes water to enter ice cavities on the Eastern side before being guided by the seabed and ice base geometry and exiting on the Western side. On the Getz Ice Shelf, Coriolis-driven circulation (Fig. 4a) brings in warm ocean water from the Amundsen Sea between Wright and Duncan Islands, and to a lesser extent between Dean and Siple Islands. Warmer water travels along the grounding line towards the West, melting the ice and gaining buoyancy and upwelling with potential freshwater, along with buoyancy and circulation input from subglacial meltwater channels ${ }^{45,46}$ (Fig. 4a). The pattern of ocean circulation under the Getz Ice Shelf is visible through higher meltwater fraction exiting the cavity at the $\sim 150-200 \mathrm{~m}$ ice draft on the eastern side of islands, most clearly Wright, Duncan and Grant (Fig. 4e). We attribute the ice speedup observed on flow units 4 to 6 (Fig. 1b), in part to the impact of circulation-driven warm ocean water reaching the grounding line in these locations, driving high rates of ice speedup and ice shelf melt ${ }^{27,30}$. Relatively warmer water seems to reach the Western Getz ${ }^{28}$ (Fig. 4). However, within the Getz cavities where tides appear to be relatively weak and melting relatively large, most of the ocean circulation is thought to be driven by the melt-induced upwelling and conducted by the evolving geometry, much like in Pine Island and Thwaites cavities ${ }^{47}$. In the case of Getz, its many ice stream tributaries, and islands acting as pinning points for the ice flow make for a complex and expectedly sinuous circulation pattern.

Ocean melt can also be enhanced by buoyancy gains at the glacier grounding zone provided by subglacial drainage outflows. Our results indicate that a number of glaciers in the Getz study region that have sped up coincide with regions of high sub-glacial water flux under the ice sheet ${ }^{45}$ (Fig. $4 \mathrm{a}$ ), including flow units 4 to 
$160^{\circ} 0^{\prime} 0^{\prime \prime} \mathrm{W}$
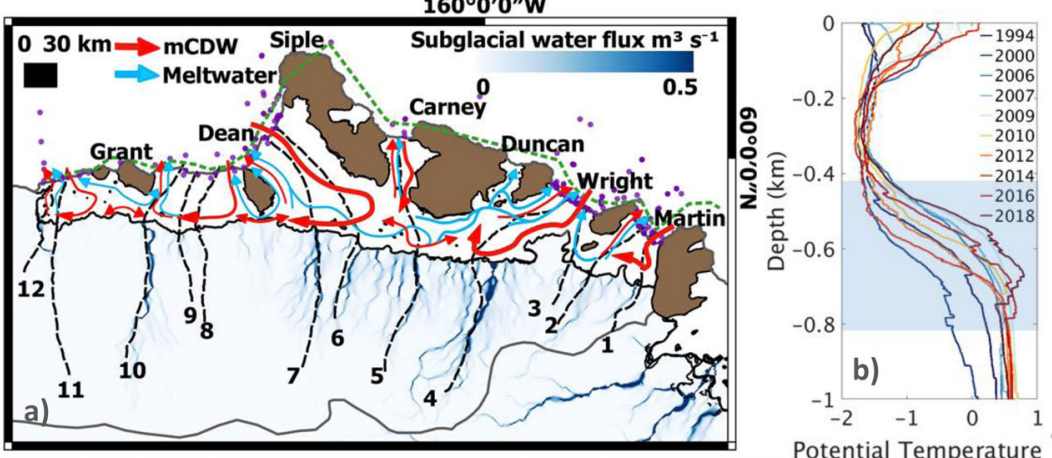

Potential Temperature ${ }^{\circ} \mathrm{C}$

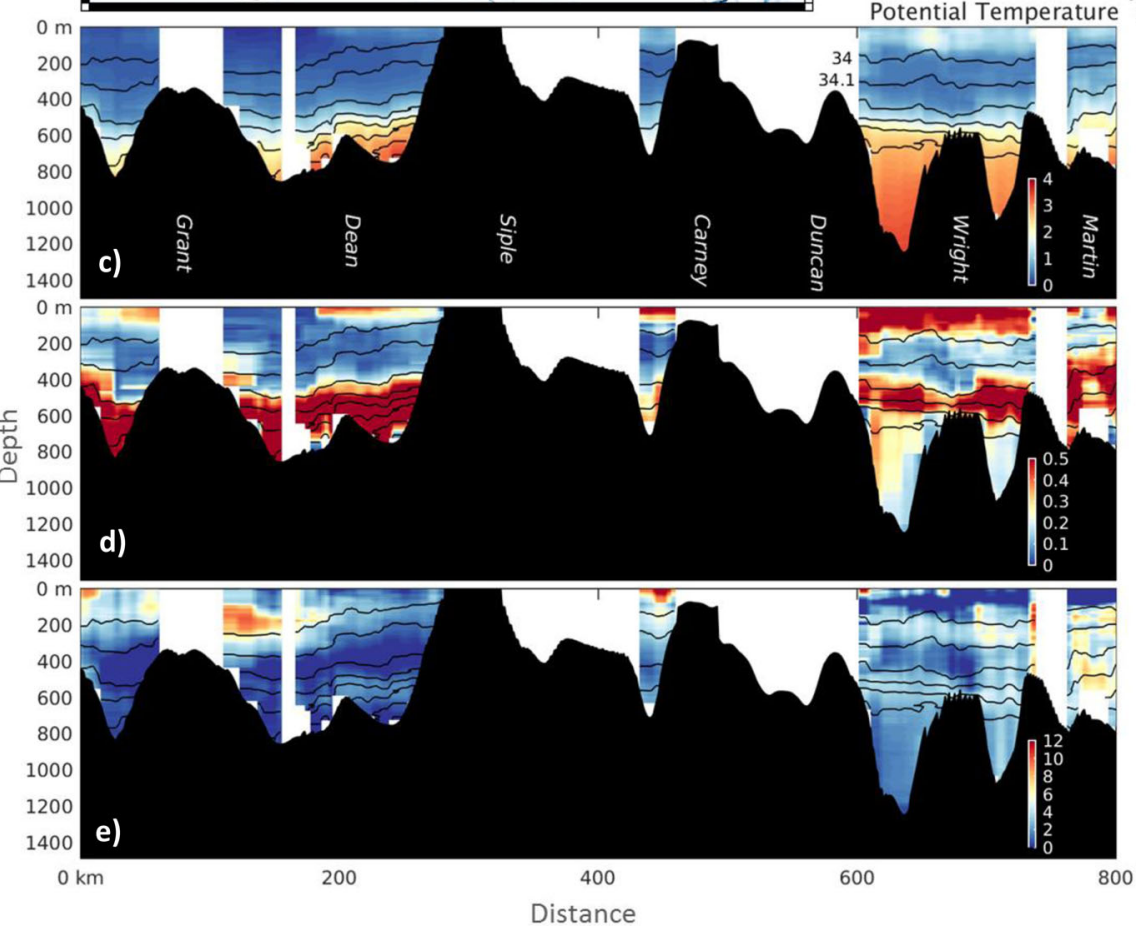

Fig. 4 Ocean characteristics along the Getz Ice Shelf. a Indicative ocean circulation under the Getz Ice Shelf cavity including both mCDW (red arrows) and meltwater (blue arrows); sub-glacial water flux under the ice sheet ${ }^{45}$ (blue scale); the location of CTD sampling sites (purple dots) and the ocean transect (green dashed line) shown in $\mathbf{c}, \mathbf{d}$ and $\mathbf{e}$. The grounding line location (solid black line ${ }^{67}$ ), inland limit of the drainage basin (solid grey line) and the location of 14 flow line profiles (dashed black lines) are also shown. b Annual mean potential temperature as depth profiles from 1994 to 2018 , from CTD measurements made at sampling sites (see a) along the Getz coastline. The shaded blue region indicates the depth of the grounding zone. c Average potential ocean temperature $\left({ }^{\circ} \mathrm{C}\right.$ ) along a transect (see a) located at the calving front of the Getz Ice Shelf. Ocean salinity between 34 and 35 Practical Salinity Unit (PSU) (black contours at 0.1 PSU intervals) are also shown, along with the sea floor bathymetry (black shading ${ }^{70}$ ) with the names of large islands annotated. d Standard deviation of ocean potential temperature $\left({ }^{\circ} \mathrm{C}\right.$ ) along the transect (see a), showing high (red) and low (blue) variability in ocean temperatures. e Meltwater Fraction $\left(\mathrm{ml.}^{-1}\right.$ ) along the transect (see Fig. 4a) at the Getz Ice Shelf calving front.

6 and DeVicq Glacier (flow unit 10). Ice melt driven by subglacial runoff or, in the Amundsen sector ocean heat, is known to decrease with distance from the grounding line $e^{14,45,48}$, as the entrainment of warm water at the ice-ocean interface increases with buoyancy and velocity, but diminishes downstream. In contrast, melt water channels under an ice shelf can extend to the ice front if the supply of warm ocean water is sustained ${ }^{49}$, or if the features are simply advected downstream. Buoyant freshwater plumes are known to drive high melt rates on marine terminating ice $^{50,51}$, and studies have shown that on Getz Ice Shelf hydrological pathways routing subglacial freshwater play a significant role in determining the location of and rate of basal melt under the ice shelf ${ }^{46}$. The change in ice speed shows that in the Getz study region, increases are locally strongest near the grounding zone and do not extend to the ice front, indicating that subglacial hydrology could also be responsible for some of the observed speedup and thinning (Fig. 1b, c). If the volume of sub-glacial water flux changes over time, as is the case on glaciers in Greenland due to seasonal surface melt ${ }^{52,53}$, this may be an unaccounted-for factor driving change in ice flow and thinning in the regions of Antarctica with high sub-glacial water flux. Most ice flow models do not account for the presence of subglacial water and our knowledge about any change in subglacial water flux over the last 25 years is limited in regions not characterised by active sub-glacial lakes. The Getz drainage basin may therefore be a valuable test region for studies investigating the coupling between sub-glacial hydrology and the ocean, and the impact this may have on the localised pattern of ice sheet dynamics in Antarctica.

Our results show that on the majority of glaciers in the Getz drainage basin, ice speeds have increased at a broadly linear rate (Supplementary Fig. 1d). Given that the Getz basin, more so than its unstable neighbours in the Eastern Amundsen Sea, is thought to be relatively immune to positive feedback processes like MISI 
and MICI due to its prograde bed topography, it is difficult to explain this trend as a runaway response to a step or oscillatory ocean forcing, at least during the past 25 years ${ }^{15}$. This suggests that the dynamic imbalance observed in Getz may primarily be a response to longer-term ocean forcing which may be anthropogenic in origin ${ }^{16}$. In the future, research programmes that deliver continuous annual monitoring of ice velocity and ocean temperatures across the study region at repeat locations will be critically important, preventing gaps in the record and enabling a more direct assessment of the link between the localised pattern and short-term variability of ice dynamics and the complex transport of ocean temperature variability.

Our 25-year-long record of ice speed shows for the first time that since 1994, widespread, linear speedup has occurred on the majority of glaciers in the Getz drainage basin of West Antarctica. Maps of change in ice flow show concentrated zones of very high speed up (over 44\%) at the grounding line on three glaciers (flow units 6, 5, and Venzke Glacier (flow unit 12)), and high speed up of over $20 \%$ on an additional three glaciers (flow units 3, 4, DeVicq Glacier (flow unit 10)) since 1994. The central region of the Getz drainage basin accounts for $46.8 \%$ of this acceleration, and contains the most spatially extensive areas of change. The pattern of ice speedup indicates a localised response on individual glaciers, demonstrating the value of high-resolution observations that resolve the detailed pattern of dynamic imbalance across the Getz drainage basin. On all glaciers, the speed increase coincides with regions of high surface lowering, with an $\sim 50 \%$ speed up corresponding to an $\sim 5 \%$ reduction in ice thickness. Our optimised model results show that $315 \mathrm{Gt}$ of ice has been lost from the Getz drainage basin since 1994, contributing $0.9 \pm 0.6 \mathrm{~mm}$ to global sea levels, and increasing the rate of ice loss by four times in the 2010s compared to the 1990s. The prograde bed topography makes the Getz region inherently less susceptible to unstable geometry driven feedbacks such as MISI or MICI compared with its Amundsen Sea neighbours, and indicates that long-term ocean warming may be driving the dynamic imbalance in this region of Antarctica. Consistent and temporally extensive sampling of both ocean temperatures and ice speed will help further our understanding of dynamic imbalance in remote areas of Antarctica in the future.

\section{Methods}

Ice velocity observations. We measured the ice speed of glaciers feeding the Getz Ice Shelf in West Antarctica over the last 25 years, using synthetic aperture radar (SAR) and optical satellite imagery acquired between January 1994 and December 2018 (Supplementary Table 1). Ice velocities were calculated using a combination of SAR and optical feature tracking ${ }^{54,55}$ and SAR interferometry techniques ${ }^{56,57}$. To map ice velocity using the Sentinel-1a and -1b satellites, we tracked the displacement of features near to or on the ice surface such as rifts, crevasses and stable amplitude variations in SAR images ${ }^{58,59}$. We apply the intensity feature tracking technique to temporally sequential pairs of Interferometric Wide (IW) swath mode Single Look Complex (SLC) SAR images ${ }^{60}$. The image pairs are co-registered using a bilinear polynomial function constrained by precise orbital state vectors, resulting in a coregistration accuracy of $5 \mathrm{~cm}^{60}$. The normalised cross correlation of SAR intensity features is calculated over evenly spaced image patches, with a window size of $64(\sim 0.9 \mathrm{~km})$ by $256(\sim 0.6 \mathrm{~km})$ pixels in the azimuth and range directions, to compute the $2 \mathrm{D}$ offset for each patch ${ }^{58,61}$. The results are converted into absolute displacement in ground range coordinates using the Antarctic digital elevation model (DEM) posted on a $1 \mathrm{~km}$ grid $^{62}$. The final velocity measurements are mosaicked and averaged to produce an annual ice speed map for each year of the study period.

Each velocity grid is post-processed to reduce noise and remove outliers by applying a low-pass (moving mean) filter over a $1 \mathrm{~km}$ by $1 \mathrm{~km}$ window, where values are rejected if the ice speed exceeds $30 \%$ of the mean value ${ }^{60}$. A second "dusting" step is applied to remove isolated pixels that are inconsistent with neighbouring velocity values, or where the measurements cover a region smaller than $0.1 \%\left(1.35 \mathrm{~km}^{2}\right)$ of the processed image size as sparse patchy data are an indicator of poor-quality measurements ${ }^{60}$. Errors in the velocity data are caused by imprecise co-registration of the SAR images, error in the auxiliary DEM, and atmospheric delay due to fluctuations in the ionosphere and tropospheric water vapour $^{35,61}$. A spatially variable error measurement was computed for each velocity grid by multiplying the signal-to-noise ratio of the cross-correlation function with the ice speed ${ }^{60}$ (Supplementary Fig. 2). The largest velocity errors are found at the highly crevassed and rapidly deforming ice front and sheer margins of the glaciers, where under $\sim 1.1 \%$ of the study region has a velocity error greater than $30 \%$. Across the full Getz drainage basin, the mean velocity error for the 2017 and 2018 maps is $7.7 \%$ and $6.8 \%$, respectively.

Historical Strip Map (SM) mode SLC SAR images acquired by the ERS-1 and ERS-2 satellites were used to measure ice speed in 1994, 1996 and 1998 using the intensity feature tracking technique ${ }^{35,58}$ (Supplementary Table 1). MEaSUREs Antarctic annual ice velocity measurements were generated from a combination of SAR and optical Landsat- 8 data using both feature tracking and interferometry techniques from data acquired over the period 2005 to 2017 (ref. ${ }^{63}$ )

(Supplementary Table 1). As with the Sentinel-1 velocity measurements, post processing filtering was applied to remove outliers where the error exceeded $0.3 \mathrm{~m} / \mathrm{d}$ standard deviation and secondary "dusting" for the historical SAR data. The spatial resolution of the velocity maps ranges from $100 \mathrm{~m}$ to $1 \mathrm{~km}$ depending on the satellite imaging geometry, the window size used in the feature tracking step, and the DEM oversampling used in the geocoding step. Overall, this study presents the most temporally extensive record of ice velocity in the Getz drainage basin of West Antarctica, with 16 annual maps from 1994 to 2018 (Supplementary Fig. 2).

Optimised ice flow model. We used the BISICLES ice sheet model to interpolate velocity observations in time and space $35,64,65$, calibrating the underlying model parameters - the vertically averaged viscosity and effective basal drag coefficientsand assuming that in the absence of observations they vary smoothly in both space and time (Supplementary Fig. 6). Scale distortions from the Polar Stereographic projection are not accounted for in the model output, therefore an additional systematic error of $1.7 \%$ is included within our discharge error estimate ${ }^{23}$. The observed and modelled ice speeds agree to within $11 \mathrm{~m}$ /year on average in all epochs (Supplementary Fig. 5a), and show the same broad spatial pattern of change in ice speed across the Getz basin (Supplementary Fig. 5b). Land Glacier and Hall Glacier (flow units 14 and 13) flow at the highest speeds, and flow units 5 and 6 have exhibited the largest percentage increase in ice speed since 1994 (Table 1). Interpretation of the underlying parameters must be treated with caution: the problem of their estimation is ill-posed and the solution depends on the choice of regularisation. Nonetheless the model is able to reproduce the observations without substantially altering the basal traction $\tau \vee$ (although the relevant model parameter, the effective basal drag coefficient $\tau \vee u$ does change substantially). In contrast, the vertically integrated effective viscosity does change, above and beyond the changes associated with the dependence of Glen's flow law on strain-rate, both in the ice shelf and in the fast-flowing streams. Supplementary Fig. 5d shows the relative change in a stiffening parameter $(\phi)$ that quantifies this excess change. A reduction in $\phi$ can be interpreted as thinning, or damage (e.g. through crevassing). These results, then, though not the only possible interpretation, are consistent with acceleration caused by thinning of the ice shelf, resulting in crevasses opening upstream. At the same time, resistance from the bed does not increase (Supplementary Fig. 5c), consistent with a Coulomb friction law and with the behaviour of the trunk of Pine Island Glacier ${ }^{66}$.

Mass balance. We calculated ice discharge from the Getz drainage basin using the 25-year record of optimised model ice flow (Supplementary Fig. 6) through a flux gate located at the grounding line $e^{67}$, and an static ice sheet thickness from BEDMAP2 (ref. ${ }^{32}$ ). We investigated the impact of change in ice thickness on the ice discharge estimates, by reducing the ice thickness by $50 \mathrm{~m}$ at the flux gate. This is greater than the observed maximum thinning of $41.8 \mathrm{~m}$ over the full study period. We found that for 2018, this had a modest impact $(1.5 \%)$ on the total ice discharge. We assumed that the surface velocity in the direction normal to the flux gate equals the depth averaged speed with an assumed ice density of $917.2 \mathrm{~kg} / \mathrm{m}^{3}$ We computed mass balance over the 25 -year study period by subtracting the ice flux out of the basin from the time-varying annual mean SMB, using a $27-\mathrm{km}$ regional climate model (RACMO 2.3p2) ${ }^{68}$. The error for the total mass balance estimate arises from the errors in the discharge and SMB. Discharge error is the combination of the percentage errors in ice thickness and velocity along the flux gate. For years of model discharge without a corresponding observation map, we assume the percentage error of the nearest observation year and add an additional standard deviation to the velocity error. The mass balance uncertainty is calculated as the discharge error combined with the error in SMB. We assume the uncertainty in the annual SMB trend to be $20 \%$ in line with previous studies ${ }^{23,69}$, and the cumulative uncertainty as the root sum square of the annual errors, assuming that they are not correlated over time. We calculated the SMB anomaly relative to the mean over the period 1979 to 2008 , and accumulated over time ${ }^{68}$ (Fig. 3b).

\section{Data availability}

The Sentinel-1 2017 and 2018 velocity data that support the findings of this study are available from PANGAEA (https://doi.org/10.1594/PANGAEA.926520). The ERS-1 and -2 velocity data that support the findings of this study are available from the ENVEO Cryoportal, "Getz IV from ERS offset tracking, 1994", "Getz IV from ERS offset tracking, 1996" and "Getz IV from ERS offset-tracking, 1998” (http://cryoportal.enveo.at/data). The MEaSUREs annual velocity data that support the findings of this study are available from the NSIDC, "NSIDC-0720" (https://doi.org/10.5067/9T4EPQXTJYW9). The 
optimised modelled velocity data that support the finding of this study are available from PANGAEA (https://doi.org/10.1594/PANGAEA.926520). The grounding line data that support the findings of this study are available from the European Space Agency (ESA) Climate Change Initiative (CCI) dashboard. The optimised ice sheet model that supports the findings of this study is available from BISICLES (https://commons.lbl.gov/display/ bisicles/BISICLES). The CTD data that support the findings of this study are available from the National Oceanographic Data Center, "NBP9402", "NBP0001", "NBP0702", "NBP0901", "NBP1005" (https://www.ncei.noaa.gov/access/world-ocean-database-select/ dbsearch.html), from PANGAEA, PS2006 (https://doi.org/10.1594/PANGAEA.847880) and PS2010 (https://doi.org/10.1594/PANGAEA.847944), from the British Oceanographic Data Centre, "JR141" (https://www.bodc.ac.uk/data/bodc_database/ctd/), from the Swedish National Data Service, "ODEN2007" (https://doi.org/10.5879/ECDS/ 2016-08-17.1/1), and from the Korea Polar Data Center, "ANA02C" (https://doi.org/ 10.22663/KOPRI-KPDC-00001176.4), “ANA04B” (https://doi.org/10.22663/KOPRIKPDC-00000714.1), “ANA06B” (https://doi.org/10.22663/KOPRI-KPDC-00000636.1) and "ANA08B" (https://doi.org/10.22663/KOPRI-KPDC-00000907.1).

Received: 19 June 2020; Accepted: 13 January 2021; Published online: 23 February 2021

\section{References}

1. Shepherd, A. et al. Mass balance of the Antarctic Ice Sheet from 1992 to 2017. Nature 558, 219-222 (2018).

2. Rignot, E. et al. Recent Antarctic ice mass loss from radar interferometry and regional climate modelling. Nat. Geosci. 1, 106-110 (2008).

3. Joughin, I., Smith, B. E. \& Holland, D. M. Sensitivity of 21 st century sea level to ocean-induced thinning of Pine Island Glacier, Antarctica. Geophys. Res. Lett. 37 (2010)

4. Shepherd, A. A reconciled estimate of ice-sheet mass balance (Science (1183)). Science 338, 1539 (2012).

5. Mouginot, J., Rignot, E. \& Scheuchl, B. Sustained increase in ice discharge from the Amundsen Sea Embayment, West Antarctica, from 1973 to 2013. Geophys. Res. Lett. 41, 1576-1584 (2014).

6. Rignot, E., Mouginot, J., Morlighem, M., Seroussi, H. \& Scheuchl, B. Widespread, rapid grounding line retreat of Pine Island, Thwaites, Smith, and Kohler glaciers, West Antarctica, from 1992 to 2011. Geophys. Res. Lett. 41, 3502-3509 (2014).

7. Smith, B. E., Gourmelen, N., Huth, A. \& Joughin, I. Connected subglacial lake drainage beneath Thwaites Glacier, West Antarctica. Cryosphere 11, 451-467 (2017).

8. Shepherd, A. et al. Trends in Antarctic ice sheet elevation and mass. Geophys. Res. Lett. 46, 8174-8183 (2019).

9. Cook, A. J. \& Vaughan, D. G. Overview of areal changes of the ice shelves on the Antarctic Peninsula over the past 50 years. Cryosphere 4, 77-98 (2010).

10. Rott, H., Skvarca, P. \& Nagler, T. Rapid collapse of northern Larsen Ice Shelf, Antarctica. Science 271, 788-792 (1996).

11. Rack, W. \& Rott, H. Pattern of retreat and disintegration of the Larsen B ice shelf, Antarctic Peninsula. Ann. Glaciol. 39, 505-510 (2004).

12. Rignot, E. et al. Accelerated ice discharge from the Antarctic Peninsula following the collapse of Larsen B ice shelf. Geophys. Res. Lett. 31, L18401 (2004)

13. Jenkins, A. et al. Observations beneath Pine Island Glacier in West-Antarctica and implications for its retreat. Nat. Geosci. 3, 468-472 (2010).

14. Dutrieux, P. et al. Strong sensitivity of pine Island ice-shelf melting to climatic variability. Science 343, 174-178 (2014).

15. Jenkins, A. et al. West Antarctic Ice Sheet retreat in the Amundsen Sea driven by decadal oceanic variability. Nat. Geosci. 11, 733-738 (2018).

16. Holland, P. R., Bracegirdle, T. J., Dutrieux, P., Jenkins, A. \& Steig, E. J. West Antarctic ice loss influenced by internal climate variability and anthropogenic forcing. Nat. Geosci. 12, 718-724 (2019).

17. Church, J. A. et al. Sea level change. In Climate Change 2013: The Physical Science Basis. Contribution of Working Group I to the Fifth Assessment Report of the Intergovernmental Panel on Climate Change (ed. Stocker, T. F. et al.) (Cambridge University Press, Cambridge, United Kingdom and New York, NY, USA, 2013).

18. Favier, L. et al. Retreat of Pine Island Glacier controlled by marine ice-sheet instability. Nat. Clim. Chang. 4, 117-121 (2014).

19. Joughin, I., Smith, B. E. \& Medley, B. Marine ice sheet collapse potentially under way for the thwaites glacier basin, West Antarctica. Science 344, 735-738 (2014).

20. DeConto, R. M. \& Pollard, D. Contribution of Antarctica to past and future sea-level rise. Nature 531, 591-597 (2016).

21. Edwards, T. L. et al. Revisiting Antarctic ice loss due to marine ice-cliff instability. Nature 566, 58-64 (2019).

22. Slater, T., Hogg, A. E. \& Mottram, R. Ice-sheet losses track high-end sea-level rise projections. Nat. Clim. Change 10 (2020).
23. Gardner, A. S. et al. Increased West Antarctic and unchanged East Antarctic ice discharge over the last 7 years. Cryosphere 12, 521-547 (2018).

24. Christie, F. D. W. et al. Glacier change along West Antarctica's Marie Byrd Land Sector and links to inter-decadal atmosphere-ocean variability. Cryosphere 12, 2461-2479 (2018).

25. Jacobs, S. et al. Getz Ice Shelf melting response to changes in ocean forcing. J. Geophys. Res. Oceans 118, 4152-4168 (2013).

26. Swithinbank, C., Williams, R. S. Jr., Ferrigno, J. G., Foley, K. M. \& Rosanova C. E. Coastal-Change and Glaciological Map of the Bakutis Coast, Antarctica: 1972-2002 (IMAP, 2003).

27. Paolo, F. S., Fricker, H. A. \& Padman, L. Volume loss from Antarctic ice shelves is accelerating. Science 348, 327-331 (2015).

28. Assmann, K. M., Darelius, E., Wåhlin, A. K., Kim, T. W. \& Lee, S. H. Warm circumpolar deep water at the Western Getz Ice Shelf Front, Antarctica. Geophys. Res. Lett. 46, 870-878 (2019).

29. Nakayama, Y., Timmermann, R., Rodehacke, C. B., Schröder, M. \& Hellmer H. H. Modeling the spreading of glacial meltwater from the Amundsen and Bellingshausen Seas. Geophys. Res. Lett. 41, 7942-7949 (2014).

30. Hogg, A. E., Gilbert, L., Shepherd, A., Muir, A. S. \& McMillan, M. Extending the record of Antarctic Ice Shelf thickness change, from 1992 to 2017. Adv. Space Res. https://doi.org/10.1016/j.asr.2020.05.030 (2020).

31. McMillan, M. et al. Increased ice losses from Antarctica detected by CryoSat2. Geophys. Res. Lett. 41, 3899-3905 (2014).

32. Fretwell, P. et al. Bedmap2: Improved ice bed, surface and thickness datasets for Antarctica. Cryosphere 7, 375-393 (2013).

33. Lenaerts, J. T. M. et al. Climate and surface mass balance of coastal West Antarctica resolved by regional climate modelling. Ann. Glaciol. 59, 29-41 (2018).

34. Donat-Magnin, M. et al. Interannual variability of summer surface mass balance and surface melting in the Amundsen sectorr, West Antarctica Cryosphere 14, 229-249 (2020).

35. Hogg, A. E. et al. Increased ice flow in Western Palmer Land linked to ocean melting. Geophys. Res. Lett. 44, 4159-4167 (2017).

36. Chuter, S. J., Martín-Español, A., Wouters, B. \& Bamber, J. L. Mass balance reassessment of glaciers draining into the Abbot and Getz Ice Shelves of West Antarctica. Geophys. Res. Lett. 44, 7328-7337 (2017).

37. Morlighem, M. et al. A mass conservation approach for mapping glacier ice thickness. Geophys. Res. Lett. 38 (2011)

38. Martín-Español, A. et al. Spatial and temporal Antarctic Ice Sheet mass trends, glacio-isostatic adjustment, and surface processes from a joint inversion of satellite altimeter, gravity, and GPS data. J. Geophys. Res. Earth Surf. 121, 182-200 (2016)

39. Rignot, E. et al. Four decades of Antarctic ice sheet mass balance from 1979-2017. Proc. Natl Acad. Sci. USA 116, 1095-1103 (2019).

40. Holschuh, N., Pollard, D., Alley, R. B. \& Anandakrishnan, S. Evaluating Marie Byrd Land stability using an improved basal topography. Earth Planet. Sci. Lett. 408, 362-369 (2014).

41. Lenaerts, J. T. M., Vizcaino, M., Fyke, J., van Kampenhout, L. \& van den Broeke, M. R. Present-day and future Antarctic ice sheet climate and surface mass balance in the Community Earth System Model. Clim. Dyn. 47, 1367-1381 (2016)

42. Schmidtko, S., Heywood, K. J., Thompson, A. F. \& Aoki, S. Multidecadal warming of Antarctic waters. Science 346, 1227-1231 (2014).

43. Orsi, A. H., Whitworth, T. \& Nowlin, W. D. On the meridional extent and fronts of the Antarctic Circumpolar Current. Deep. Sea Res. 1 Oceanogr. Res. Pap. 42, 641-673 (1995).

44. Dotto, T. S. et al. Wind-driven processes controlling oceanic heat delivery to the Amundsen Sea, Antarctica. J. Phys. Oceanogr. 49, 2829-2849 (2019).

45. Le Brocq, A. M. et al. Evidence from ice shelves for channelized meltwater flow beneath the Antarctic Ice Sheet. Nat. Geosci. 6, 945-948 (2013).

46. Wei, W. et al. Getz Ice Shelf melt enhanced by freshwater discharge from beneath the West Antarctic Ice Sheet. Cryosphere 14, 1399-1408 (2020).

47. Nakayama, Y. et al. Pathways of ocean heat towards Pine Island and Thwaites grounding lines. Sci. Rep. 9, 1-9 (2019).

48. Drews, R. et al. Constraining variable density of ice shelves using wide-angle radar measurements. Cryosphere 10, 811-823 (2016).

49. Gourmelen, N. et al. Channelized melting drives thinning under a rapidly melting Antarctic Ice Shelf. Geophys. Res. Lett. 44, 9796-9804 (2017).

50. Jenkins, A. Convection-driven melting near the grounding lines of ice shelves and tidewater glaciers. J. Phys. Oceanogr. 41, 2279-2294 (2011).

51. Slater, D. A., Goldberg, D. N., Nienow, P. W. \& Cowton, T. R. Scalings for submarine melting at tidewater glaciers from buoyant plume theory. J. Phys. Oceanogr. 46, 1839-1855 (2016)

52. Sundal, A. V. et al. Melt-induced speed-up of Greenland ice sheet offset by efficient subglacial drainage. Nature 469, 521-524 (2011).

53. Nienow, P. W., Sole, A. J., Slater, D. A. \& Cowton, T. R. Recent advances in our understanding of the role of meltwater in the Greenland Ice Sheet System. Curr. Clim. Change Rep. 3, 330-344 (2017). 
54. Rosanova, C. E., Lucchitta, B. K. \& Ferrigno, J. G. Velocities of Thwaites Glacier and smaller glaciers along the Marie Byrd Land coast, West Antarctica. Ann. Glaciol. 27, 47-53 (1998).

55. Michel, R. \& Rignot, E. Flow of Glaciar Moreno, Argentina, from repeat-pass Shuttle Imaging Radar images: comparison of the phase correlation method with radar interferometry. J. Glaciol. 45, 93-100 (1999).

56. Goldstein, R. M., Zebker, H. A. \& Werner, C. L. Satellite radar interferometry: two-dimensional phase unwrapping. Radio Sci. 23, 713-720 (1988).

57. Joughin, L. R., Kwok, R. \& Fahnestock, M. A. Interferometric estimation of three-dimensional ice-flow using ascending and descending passes. IEEE Trans. Geosci. Remote Sens. 36, 25-37 (1998).

58. Strozzi, T., Luckman, A., Murray, T., Wegmüller, U. \& Werner, C. L. Glacier motion estimation using SAR offset-tracking procedures. IEEE Trans. Geosci. Remote Sens. 40, 2384-2391 (2002).

59. Paul, F., Kääb, A. \& Haeberli, W. Mapping of rock glaciers with optical satellite imagery. In Permafrost: Extended Abstracts Reporting Current Research and new Information (eds. Haeberli, W. \& Brandová, D.) 125-126 (International Conference on Permafrost, Zurich, Switzerland, 2003).

60. Lemos, A., Shepherd, A., McMillan, M. \& Hogg, A. E. Seasonal variations in the flow of land551 terminating glaciers in central-west Greenland using Sentinel-1 imagery. Remote Sens. 10, 12 (2018).

61. Nagler, T., Rott, H., Hetzenecker, M., Wuite, J. \& Potin, P. The Sentinel-1 Mission: new opportunities for ice sheet observations. Remote Sens. 7, 9371-9389 (2015).

62. Bamber, J. L., Gomez-Dans, J. L. \& Griggs, J. A. A new $1 \mathrm{~km}$ digital elevation model of the Antarctic derived from combined satellite radar and laser data Part 1: data and methods. Cryosphere 3, 101-111 (2009).

63. Mouginot, J., Rignot, E., Scheuchl, B. \& Millan, R. Comprehensive annual ice sheet velocity mapping using Landsat-8, Sentinel-1, and RADARSAT-2 Data. Remote Sens. 9, 364 (2017).

64. Cornford, S. L. et al. Century-scale simulations of the response of the West Antarctic Ice Sheet to a warming climate. Cryosphere 9, 1579-1600 (2015).

65. Minchew, B. M., Gudmundsson, G. H., Gardner, A. S., Paolo, F. S. \& Fricker H. A. Modeling the dynamic response of outlet glaciers to observed ice-shelf thinning in the Bellingshausen Sea Sector, West Antarctica. J. Glaciol. 64 333-342 (2018).

66. Joughin, I., Smith, B. E. \& Schoof, C. G. Regularized Coulomb friction laws for ice sheet sliding: application to Pine Island Glacier, Antarctica. Geophys. Res. Lett. 46, 4764-4771 (2019).

67. Rignot, E. \& Mouginot, J. B. S. MEaSUREs Antarctic Grounding Line from Differential Satellite Radar Interferometry, Version 2 (NASA National Snow and Ice Data Center Distributed Active Archive Center, Boulder, Colorado, USA) https://doi.org/10.5067/IKBWW4RYHF1Q (2016).

68. Melchior Van Wessem, J. et al. Modelling the climate and surface mass balance of polar ice sheets using RACMO2 - Part 2: Antarctica (1979-2016). Cryosphere 12, 1479-1498 (2018).

69. Wouters, B. et al. Dynamic thinning of glaciers on the Southern Antarctic Peninsula. Science 348, 899-903 (2015).

70. Schaffer, J. et al. A global, high-resolution data set of ice sheet topography, cavity geometry, and ocean bathymetry. Earth Syst. Sci. Data 8, 543-557 (2016).

\section{Acknowledgements}

This work was led by the School of Earth and Environment at the University of Leeds, with support from the NERC Centre for Polar Observation and Modelling
(CPOM300001). The authors gratefully acknowledge the ESA, the National Aeronautics and Space Administration, the Japan Aerospace Exploration Agency and the Canadian Space Agency for the acquisition of ERS-1 and -2 (C1P9925), Sentinel-1, Landsat-8, ALOS PALSAR and RADARSAT data, respectively. We acknowledge the use of datasets produced through the ESA Antarctic Ice Sheet Climate Change Initiative (AIS_CCI) project and the NASA Measures programme for funding the development of long-term climate data records from satellite observations. Anna E. Hogg was supported by the NERC DeCAdeS project (NE/T012757/1) and ESA Polar+ Ice Shelves project (ESA-IPLPOE-EF-cb-LE-2019-834). Pierre Dutrieux was supported by NSF awards 1643285 , 1644159, and a Columbia University Climate and Life Fellowship. Tae-Wan Kim from the Korea Polar Research Institute, grant KOPRI PE20160.

\section{Author contributions}

H.L.S., A.E.H. and A.S. designed the work. H.L.S., A.E.H., J.W., T.N. and A.K. processed the ice velocity observations. S.C. performed the ice sheet model simulations. P.D. and T.W.K. provided oceanographic data. D.F. processed the grounding line observations. L.G. processed the surface elevation change observations. T.S. extracted surface mass balance data. H.L.S. performed the analysis. H.L.S. and A.E.H. wrote the manuscript. All authors contributed to scientific discussion, interpretation of the results and contributed to the manuscript.

\section{Competing interests}

The authors declare no competing interests.

\section{Additional information}

Supplementary information The online version contains supplementary material available at https://doi.org/10.1038/s41467-021-21321-1.

Correspondence and requests for materials should be addressed to H.L.S.

Peer review information Nature Communications thanks the anonymous reviewer(s) for their contribution to the peer review of this work. Peer reviewer reports are available.

Reprints and permission information is available at http://www.nature.com/reprints

Publisher's note Springer Nature remains neutral with regard to jurisdictional claims in published maps and institutional affiliations.

Open Access This article is licensed under a Creative Commons Attribution 4.0 International License, which permits use, sharing, adaptation, distribution and reproduction in any medium or format, as long as you give appropriate credit to the original author(s) and the source, provide a link to the Creative Commons license, and indicate if changes were made. The images or other third party material in this article are included in the article's Creative Commons license, unless indicated otherwise in a credit line to the material. If material is not included in the article's Creative Commons license and your intended use is not permitted by statutory regulation or exceeds the permitted use, you will need to obtain permission directly from the copyright holder. To view a copy of this license, visit http://creativecommons.org/ licenses/by/4.0/.

(C) The Author(s) 2021 